\title{
Side by Side Comparison of Chemical Compounds Generated by Aqueous Pretreatments of Maize Stover, Miscanthus and Sugarcane Bagasse
}

\author{
Leonardo D. Gómez • Ruben Vanholme • Susannah Bird • Geert Goeminne • \\ Luisa M. Trindade • Igor Polikarpov • Rachael Simister • Kris Morreel • Wout Boerjan • \\ Simon J. McQueen-Mason
}

Published online: 3 June 2014

(C) The Author(s) 2014. This article is published with open access at Springerlink.com

\begin{abstract}
In order to examine the potential for coproduct generation, we have characterised chemical compounds released by a range of alkaline and acidic aqueous pretreatments as well as the effect of these pretreatments on the saccharification ability of the lignocellulosic material. Comparative experiments were performed using three biomass types chosen for their potential as second-generation biofuel feedstocks: maize stover, miscanthus and sugarcane bagasse. The release of lignin from the feedstock correlated with the residual biomass saccharification potential, which was consistently higher after alkaline pretreament for all three feedstock types.
\end{abstract}

Leonardo D. Gómez and Ruben Vanholme contributed equally in this work.

Electronic supplementary material The online version of this article (doi:10.1007/s12155-014-9480-2) contains supplementary material, which is available to authorized users.

L. D. Gómez · S. Bird · R. Simister · S. J. McQueen-Mason $(\bowtie)$

CNAP, Biology Department, University of York, PO box 374,

York YO10 5DD, UK

e-mail: simon.mcqueenmason@york.ac.uk

R. Vanholme $\cdot$ G. Goeminne $\cdot$ K. Morreel $\cdot$ W. Boerjan Department of Plant Systems Biology, VIB, Technologiepark 927, 9052 Ghent, Belgium

R. Vanholme $\cdot$ G. Goeminne $\cdot$ K. Morreel $\cdot$ W. Boerjan

Department of Plant Biotechnology and Bioinformatics, Ghent

University, Technologiepark 927, 9052 Ghent, Belgium

\section{M. Trindade}

Wageningen UR Plant Breeding, Wageningen University and Research Centre, P.O. Box 386, 6700 AJ Wageningen, The

Netherlands

I. Polikarpov

Instituto de Física de São Carlos, Universidade de São Paulo, Caixa

Postal 369, 13560-970 São Carlos, SP, Brazil
Alkaline pretreatment released more complex mixtures of pentose and hexose sugars into the pretreatment liquor than did acid pretreatment. In addition, complex mixtures of aromatic and aliphatic compounds were released into pretreatment liquors under alkaline conditions, in a temperaturedependent manner, but far less so under acidic conditions. We show that the three feedstocks characterised interact with the pretreatment conditions in a specific manner to generate different ranges of products, highlighting the need to tailor pretreatments to both the starting feedstock and desired outcomes.

Keywords Biorefineries $\cdot$ Biomass chemicals Pretreatment . Lignin $\cdot$ Phenolics $\cdot$ Pentoses $\cdot$ Maize $\cdot$ Miscanthus ·

Sugarcane bagasse

\section{Introduction}

The coproduction of value-added chemicals from biomass processing may best be achieved from the basis of understanding the range of products released from the feedstock under different processing conditions. This knowledge will allow the identification of processing conditions suitable for the release of both sugars for fermentation and value-added products. The noncrystalline nature of hemicelluloses makes them susceptible to extraction during pretreatments. Different thermochemical pretreatments will cause removal of the hemicellulose fraction to different extents. Various reports on the extent of this removal have been published and show that this varies between the species of biomass and conditions used $[1,2]$. The insoluble polysaccharide fraction left after efficient separation of hemicelluloses is enriched in glucose, which on saccharification provides substrates similar to those used in 
classic fermentation of starch- or sucrose-derived sugars, with lower content of problematic pentoses [3].

Lignin is a complex aromatic polymer that embeds the polysaccharide fraction in the biomass and provides the major constraint for hydrolytic deconstruction of polysaccharides. However, it represents up to $30 \%$ of the biomass and has diverse existing and potential industrial applications [4].

The energy crops proposed as feedstock for biorefineries should have a high productivity and nutrient use efficiency to reach a favourable balance of emissions compared to oilderived products. In addition, it is important that secondgeneration biofuel feedstocks do not negatively impact on global food security [5, 6]. Maize stover, sugarcane bagasse and miscanthus are all favoured as highly available or productive nonfood feedstocks for biomass biorefining and biofuels. Maize is a major crop grown for grain and gives rise to very large volumes of stem and leaf residues, on average 5.2 tons DM/ha [6], and constitute a potential source of biomass for biofuel production [7]. In the USA, maize stover constitutes a by-product of grain ethanol and food production and its integration in the biorefining process represents an addition to the value chain. Sugarcane bagasse is also an attractive feedstock for biorefineries (on average 11 tons/ha [6]) as it constitutes a by-product of the sugar and first-generation biofuel industries in tropical countries such as Brazil. In Brazil, a typical sugar processing plant produces on average 90 tons DM/ha of bagasse [8]. This bagasse has been partially incorporated into the sugarcane industry for energy generation by burning in power plants that generate heat and electricity for the sugar mills and export the excess into the grid. The utilisation of bagasse for cellulosic ethanol is an attractive possibility for increasing the sustainability around the sugarcane industry [8]. Miscanthus is a dedicated perennial energy crop and has been proposed as a model of a low input agricultural crop. It is at present used for burning in power plants but it is also proposed as a potential feedstock for cellulosic ethanol given the large yields and it's adaptability to marginal lands [9]. Yields of more than 40 ton $\mathrm{DM} /$ ha have been achieved for miscanthus in southern Europe and USA [6].

Whatever the biomass of choice, there is a need to use (thermochemical) pretreatments to potentiate the effective enzymatic hydrolysis of polysaccharides for fermentation [10]. Pretreatments have been considered for a long time as the key to take the biochemical conversion of biomass to levels which are compatible with industrial applications [11]. A great deal of research has been put into the development of different pretreatments over the last 10 years, and the literature is rich in diverse and creative approaches to increase the efficiency of pretreatments in terms of increased fuel production after fermentation ([12] and references therein). An interesting new approach is to evaluate pretreatments in terms of their potential for the cogeneration of value-added chemicals in addition to their ability to potentiate enzymatic hydrolysis [13].

In the present work, we characterise the sugars and lignin derivatives present in the pretreatment liquor of maize stover, miscanthus and sugarcane bagasse under a range of acidic and alkaline pretreatment conditions. This provides a detailed picture of the conditions necessary for favouring the production of different molecules and also allows a horizontal comparison of the compounds generated between species. In order to examine the impacts of temperature and acid or alkali concentration on pretreatment effectiveness, we first carried out experiments with a fixed concentration of $\mathrm{NaOH}$ or $\mathrm{H}_{2} \mathrm{SO}_{4}$ in a range of different temperatures and subsequently looked at varying chemical concentrations at low $\left(20^{\circ} \mathrm{C}\right)$ or high $\left(180^{\circ} \mathrm{C}\right)$ temperatures.

\section{Material and Methods}

\section{Biomass Feedstock and Characterisation}

Maize biomass was obtained from INRA France. M2 maize was grown at INRA Lusignan (France) under field conditions and harvested at R6 stage (silage) removing the cobs. The dry biomass was ground using a hammer mill and sieved to 1-mm particles. The Miscanthus sinensis accession MS-90-2 was grown under field conditions at the Wageningen University (The Netherlands), harvested at maturity and ground to 1-mm particles using a hammer mill. Sugarcane bagasse was kindly provided by the Cosan Group (Ibaté/SP, Brazil) after sucrose extraction and ground to 1-mm particles.

Cell wall composition was determined essentially as described in Torres et al. (22), which derives from Goering and Van Soest [14] Half a gram of biomass was weighed into a ANKOM filter bag (ANKOM Technology Corporation, Fairpoint, NY) and the following parameters were determined: neutral detergent fibre (NDF), acid detergent fibre (ADF) and permanganate lignin (pLig). All analyses were performed in duplicate and were carried out using an ANKOM 2000 Fiber Analyzer (ANKOM Technology Corporation, Fairpoint, NY). Stem total cell wall, cellulose (Cel), hemicellulose (Hem) and permanganate lignin ( $\mathrm{pLig}$ ) contents were derived from detergent fibre parameters as follows: NDF corresponds to the total cell wall content; Cel was determined as the difference between acid detergent fibre (ADF) and permanganate lignin ( $\mathrm{pLig}$ ) and Hem was determined as the difference between NDF and ADF.

\section{Pretreatment Conditions}

Biomass $(400 \mathrm{mg}$ ) was pretreated in $23-\mathrm{mL}$ pressure bombs (Parr Instruments, Moline, IL), using $16 \mathrm{~mL}$ of pretreatment solution. Pretreatments were performed during $30 \mathrm{~min}$ to 
determine the effect of increasing temperatures and $40 \mathrm{~min}$ in the presence of increasing chemical concentrations. Three technical replicates were used for each condition. After cooling to room temperature, the liquid and solid fraction were separated by centrifugation at $4,000 \mathrm{~g}$ for $15 \mathrm{~min}$. The liquid (pretreatment liquor fraction) was recovered for further analysis. The solids were washed three times in ethanol $(5 \mathrm{~mL}$ for $10 \mathrm{~min}$ at $20^{\circ} \mathrm{C}$ ) before further processing.

\section{Total Sugar Content in Pretreatment Liquors}

Monosaccharide composition in the liquor fraction obtained from each pretreatment condition was determined by ion chromatography. Two $\mathrm{mL}$ of acidic liquor samples were initially neutralised with $1.33 \mathrm{~mL}$ barium hydroxide solution $(150 \mathrm{mM})$, followed by barium carbonate powder. Alkaline liquor samples $(2 \mathrm{~mL})$ were neutralised with $0.4 \mathrm{~mL}$ of $2 \mathrm{~N}$ $\mathrm{HCl}$. All samples were individually titrated to $\mathrm{pH}$ 7.0. Samples were adjusted to a final volume of $12 \mathrm{~mL}$ and centrifuged at $4,000 \mathrm{~g} ; 0.5 \mathrm{~mL}$ of the neutralised liquor fraction was transferred to microcentrifuge tube and vacuum dried. Hydrolysis using $500 \mu \mathrm{L}$ of $2 \mathrm{M}$ trifluoroacetic acid (TFA) was carried out at $100{ }^{\circ} \mathrm{C}$ for $4 \mathrm{~h}$. After cooling to room temperature, samples were dried and twice washed with $200 \mu \mathrm{L}$ of isopropanol. Hydrolysates were resuspended in $200 \mu \mathrm{L}$ of water. Monosaccharide analysis of the TFA treated pretreatment liquor $(1 \mathrm{~mL})$ was performed by high performance anion-exchange chromatography (HPAEC) (Dionex IC 3000) on a Dionex Carbopac PA-20 column with integrated amperometry detection [15]. The separated monosaccharides were quantified using external calibration with an equimolar mixture of nine monosaccharide standards (arabinose, fucose, galactose, galacturonic acid, glucose, glucuronic acid, mannose, rhamnose and xylose), which were subjected to TFA hydrolysis in parallel with the samples. The mass of sugars is expressed per mass of original biomass

\section{Acetyl Bromide Soluble Lignin}

The total lignin content was determined using the acetyl bromide method [16]. Note that because of the heterogeneity of lignin and its occurrence within a complex cell wall matrix, there is no single technique to accurately measure lignin amount [17]. Acetyl bromide soluble lignin (ABSL) levels have been reported to be influenced by lignin composition [18], by UV-absorbing soluble substances that are not efficiently removed during solvent washing of the cell wall material [19] and by xylan degradation [20]. Despite these possible interferences, ABSL is commonly used as a proxy for lignin amount. Plant materials obtained after each pretreatment condition were washed with ethanol $(10 \mathrm{~mL}, 10 \mathrm{~min}$ at $20{ }^{\circ} \mathrm{C}$ ) to remove soluble compounds. Pretreatment liquor samples were dried. Next, $3.5 \mathrm{mg}$ of each sample was weighed into a 2-mL cap tube and $250 \mu \mathrm{L}$ of freshly prepared acetyl bromide solution ( $25 \% v / v$ acetyl bromide/glacial acetic acid) was added. Samples were incubated at $50{ }^{\circ} \mathrm{C}$ for $3 \mathrm{~h}$. After cooling at room temperature, the hydrolysate was transferred to a 5-mL volumetric flask. One $\mathrm{mL}$ of $2 \mathrm{M} \mathrm{NaOH}$ was added to the $2-\mathrm{mL}$ tube to generate the acetyl bromide excess before transfer to a volumetric flask; $175 \mu \mathrm{L}$ of hydroxylamine- $\mathrm{HCl}$ was added to each sample which was vortexed vigorously. Finally, the volume was adjusted to $5 \mathrm{~mL}$ with glacial acetic acid and the absorbance was measured at $280 \mathrm{~nm}$. The ABSL (\%) was determined using the extinction coefficient $17.75 \mathrm{~L} \mathrm{~g}^{-1} \mathrm{~cm}^{-1}[16]$.

\section{Furfural and Hydroxymethyl Furfural Determination}

Liquor fractions obtained from each pretreatment condition were neutralised as described above and subjected to chromatography using a Luna ${ }^{\circledR} 5 \mu \mathrm{m} \mathrm{C18(2)} 100 \AA$ LC Column $150 \times 4.6 \mathrm{~mm}$ (Phenomenex, Cheshire, UK), together with a C18 $4 \times 2.0 \mathrm{~mm}$ ID guard column (Phenomenex, Cheshire, UK) to quantify furfural and HMF content. Analyses were carried out using a Surveyor HPLC (Thermo electron Corporation, Hemel Hempstead, UK), with an elution system of acetonitrile by reversed-phase in an isocratic gradient (5\% acetonitrile and $95 \%$ deionised water) at $1 \mathrm{~mL} / \mathrm{min}$. The eluted furfuraldehydes were detected by UV absorbance at $284 \mathrm{~nm}$ using a Finnigan Surveyor PDA Plus detector. The furfurals were quantified by interpolation of a calibration curve within the range of $0.005-50 \mu \mathrm{g} / \mathrm{mL}$ in water.

\section{Analysis of Phenolics in the Pretreatment Liquors}

The neutralised lyophilized pretreatment liquors of water and $\mathrm{H}_{2} \mathrm{SO}_{4}$ pretreated samples were dissolved in $2 \mathrm{~mL}$ of water whereas neutralised pretreatment liquors of $\mathrm{NaOH}$ pretreated samples were dissolved in $10 \mathrm{~mL}$ of water. Solid phase extraction was performed on $2 \mathrm{~mL}$ of the dissolved samples using an Extract Clean $100 \mathrm{mg} / 1.5 \mathrm{~mL}$ C18-SPE column (Grace, Deerfield, IL, USA) and a vacuum manifold. The SPE column was preconditioned with $0.5 \mathrm{~mL}$ methanol followed by $1.5 \mathrm{~mL}$ of water). Two $\mathrm{mL}$ of the sample was applied on the column which was then rinsed with $300 \mu \mathrm{L}$ of water. Flow-through and wash were discarded. The sample was then eluted with $1.10 \mathrm{~mL}$ of acetonitrile (ACN). The eluent was dried using a speedvac. Liquid-liquid extraction was performed with $80 \mu \mathrm{L} / 80 \mu \mathrm{L}$ cyclohexane/water for maize stover samples and $100 \mu \mathrm{L} / 100 \mu \mathrm{L}$ cyclohexane/ water for miscanthus and sugarcane bagasse samples; $70 \mu \mathrm{L}$ of the water phase was transferred to an ultra performance liquid chromatography (UPLC) vial. Of this, $15 \mu \mathrm{L}$ of the lower water phase was injected on a Waters Acquity UPLC ${ }^{\circledR}$. As such, a certain fraction of the original $16 \mathrm{~mL}$ pretreatment liquor was analysed. For the $\mathrm{NaOH}$ pretreated samples: a 
1/213 fraction for sugarcane bagasse and miscanthus (i.e., the initial portion taken from the total pretreatment liquor volume ( $2 \mathrm{~mL} / 16 \mathrm{~mL}$ ), multiplied by the dilution factor because samples were too concentrated $(2 \mathrm{~mL} / 10 \mathrm{~mL})$, multiplied by the portion of the liquid-liquid aqueous phase that is injected on the UPLC for analysis $(15 \mathrm{~mL} / 80 \mathrm{~mL})$ ) and 1/266 for maize stover; for the $\mathrm{H}_{2} \mathrm{SO}_{4}$ pretreated samples: $1 / 42.7$ for sugarcane bagasse and miscanthus, 1/53.4 for maize stover. Later in the analysis, all peak areas were subjected to a correction factor inversely proportional to the fraction taken to enable comparing the feedstocks with a different analysed fraction. The UPLC system was equipped with a BEH C18 column $(2.1 \times 150 \mathrm{~mm}, 1.7 \mu \mathrm{M})$, coupled to a Synapt Q-Tof (Waters Corporation, Milford, MA, USA). A gradient of two buffers was used: buffer A (99/1/0.1, $\mathrm{H}_{2} \mathrm{O} / \mathrm{ACN} /$ formic acid, pH 3), buffer B (99/1/0.1, ACN/ $\mathrm{H}_{2} \mathrm{O} /$ formic acid, $\left.\mathrm{pH} 3\right)$; $95 \%$ A for $0.1 \mathrm{~min}$ decreased to $50 \% \mathrm{~A}$ in $30 \mathrm{~min}(350 \mu \mathrm{L} / \mathrm{min}$, column temperature $40^{\circ} \mathrm{C}$ ). The flow was diverted to the mass spectrometer equipped with an electrospray ionisation source and lockspray interface for accurate mass measurements. The mass spectrometer (MS) source parameters were capillary voltage, $1.5 \mathrm{kV}$; sampling cone, $40 \mathrm{~V}$; extraction cone, $4 \mathrm{~V}$; source temperature, $120^{\circ} \mathrm{C}$; desolvation temperature, $350{ }^{\circ} \mathrm{C}$; cone gas flow, $50 \mathrm{~L} / \mathrm{h}$ and desolvation gas flow, $550 \mathrm{~L} / \mathrm{h}$. The collision energy for the trap and transfer cells were 6 and $4 \mathrm{~V}$, respectively. For data acquisition, the dynamic range enhancement mode was activated. Full-scan data were recorded in negative centroid V-mode; the mass range between $\mathrm{m} / \mathrm{z} 100$ and 1,000, with a scan speed of $0.2 \mathrm{~s} /$ scan, with Masslynx software (Waters). Leucin-enkephalin (400 pg/ $\mathrm{LL}$ solubilised in water/ACN 1:1 (vol:vol), with $0.1 \%$ formic acid) was used for the lock mass calibration, with scanning every $10 \mathrm{~s}$ with a scan time of $0.5 \mathrm{~s}$. From the resulting chromatograms, 13,936 peaks were integrated and aligned via Masslynx ${ }^{\circledR}$ software. For principal component analysis (PCA), this peaklist was further filtered for peaks that appeared at least once in all three replicates of the same conditions and for which the peak was at least in one sample above intensity 200. This resulted in 3,572 peaks for $\mathrm{H}_{2} \mathrm{SO}_{4}$ pretreated samples and 5,294 peaks for $\mathrm{NaOH}$ pretreated samples. PCA was performed in R software via the 'prcomp' command. As stated above, all peak areas were multiplied by a correction factor to enable comparing the feedstocks with a different analysed fraction.

\section{Results}

Compositional Analysis of the Three Biomass Feedstocks Studied

The biomass was grown and harvested to reflect a typical case study for the three species (see "Materials and Methods"). The composition of the three biomass feedstocks showed clear differences between the three species studied, and the individual composition is consistent with the range of values previously published for these feedstocks (Table 1) [21-24]. The total cell wall content in maize stover is lower than in the other biomasses, showing a higher proportion of soluble materials in the original biomass. Interestingly, the cellulose content in the materials is inversely correlated with the percentage of hemicellulose. This differential composition will have a clear effect in the type of compounds released during pretreatment.

Effect of Temperature in Alkaline and Acidic Pretreatments on Sugar Release into Pretreatment Liquors

There is a considerable diversity of biomass pretreatment conditions in the literature, in terms of nature and severity. The most common conditions, however, involve the use of dilute acid or alkali to disrupt the structure of the biomass to make the polysaccharides more accessible to the hydrolytic enzymes [10]. The strength of such pretreatment conditions is a function of the treatment time, the $\mathrm{pH}$ of the medium and the temperature [25]. In order to select a temperature to perform alkaline and acid pretreatments in maize stover, miscanthus and sugarcane bagasse, we subjected feedstock from the three materials during $30 \mathrm{~min}$ to increasing temperature conditions in the presence of $0.2 \mathrm{~N}$ of either $\mathrm{NaOH}$ or $\mathrm{H}_{2} \mathrm{SO}_{4}$. Such pretreatments often cause substantial quantities of sugars to be released from the biomass, particularly from the hemicellulose fraction, and these could be used in fermentation, anaerobic digestion or chemical applications to generate additional value.

Figure 1 (and Supplemental Tables 1 and 2) shows that the amount of sugars present in the pretreatment liquor (determined as sugars after TFA treatment) is highly dependent on the feedstock and condition used. In general, the pretreatment liquor of maize stover released more sugars than those of miscanthus or sugarcane bagasse, while the amount of sugars in the pretreatment liquor of miscanthus and sugarcane bagasse were in the same range. The lower proportion of total cell wall, as a percentage of dry matter, observed in maize (Table 1) could explain the larger amount of sugars released in the pretreatment liquors in this biomass. In addition, there was an increment in the amount of sugars in the liquor with increasing temperatures, an effect which was more pronounced for acidic pretreatments as compared to the alkaline pretreatments. For temperatures up to $110{ }^{\circ} \mathrm{C}$, pretreatment liquor of alkaline conditions contained larger amounts of sugars compared to those of acidic conditions for all feedstocks used. However, at $180^{\circ} \mathrm{C}$, the amount of sugars in acid pretreated liquors was higher as compared to those in alkaline liquors for both miscanthus and sugarcane bagasse samples.

The monosaccharide composition of these liquors show that, in most of the conditions used, glucose or xylose were 
Table 1 Cell wall composition of the three biomasses

\begin{tabular}{lllll}
\hline Biomass & Total cell wall $(\%$ of dry matter) & Cellulose $(\%$ of cell wall) & Hemicellulose (\% of cell wall) & Lignin (\% of cell wall) \\
\hline Maize stover & $54.177( \pm 1.06)$ & $38.518( \pm 2.397)$ & $48.537( \pm 0.767)$ & $12.945( \pm 1.813)$ \\
Miscanthus & $87.559( \pm 0.777)$ & $46.547( \pm 1.855)$ & $33.737( \pm 0.599)$ & $19.716( \pm 1.663)$ \\
Sugarcane bagasse & $88.794( \pm 0.468)$ & $51.802( \pm 2.155)$ & $31.690( \pm 0.594)$ & $16.509( \pm 2.342)$
\end{tabular}

Values between brackets show standard deviation between determinations, $n=4$

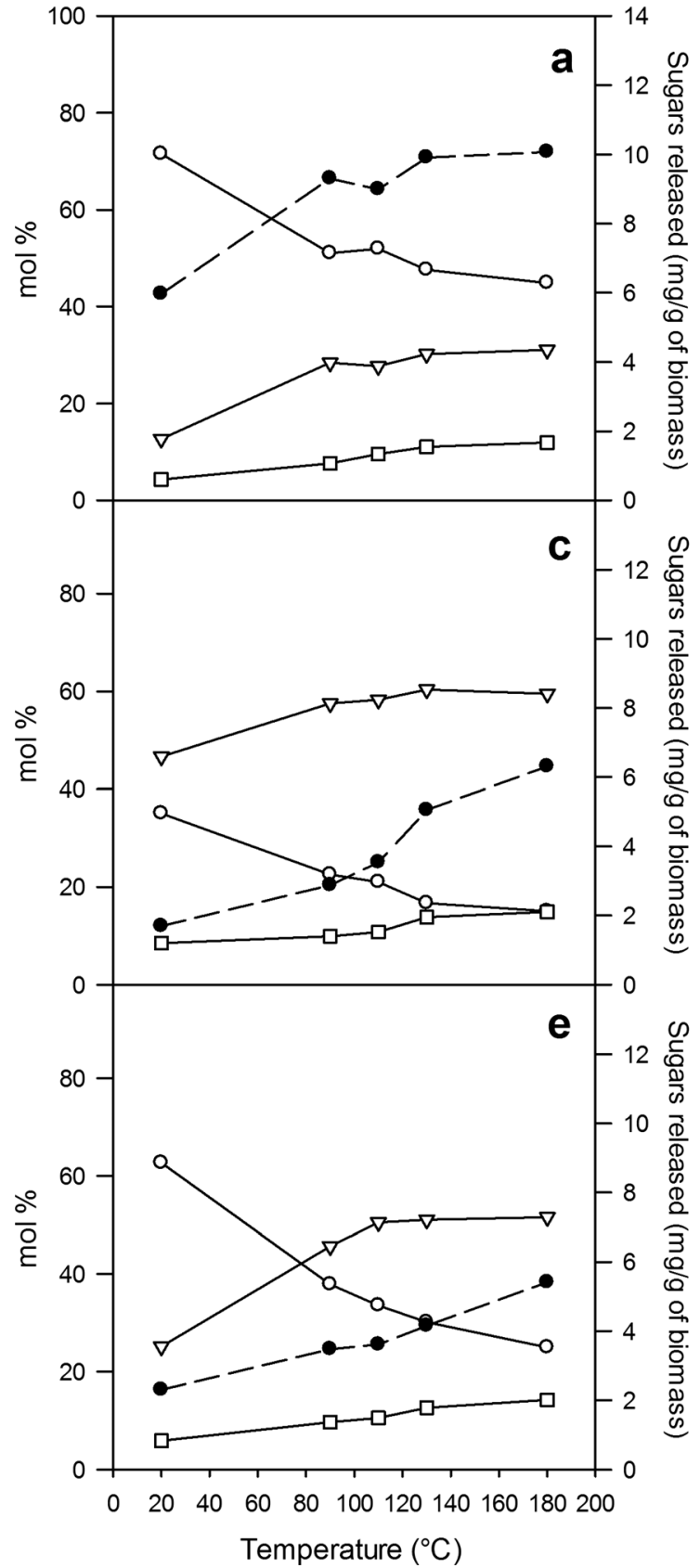

Fig. 1 Amount of sugars released and monosaccharide composition of the pretreatment liquor at different temperatures. Total sugars released after TFA treatment and mol\% composition of the TFA-released monosaccharides of $0.2 \mathrm{~N} \mathrm{NaOH}(\mathbf{a}, \mathbf{c}, \mathbf{e})$ or $\mathrm{H}_{2} \mathrm{SO}_{4}(\mathbf{b}, \mathbf{d}, \mathbf{f})$ from maize stover

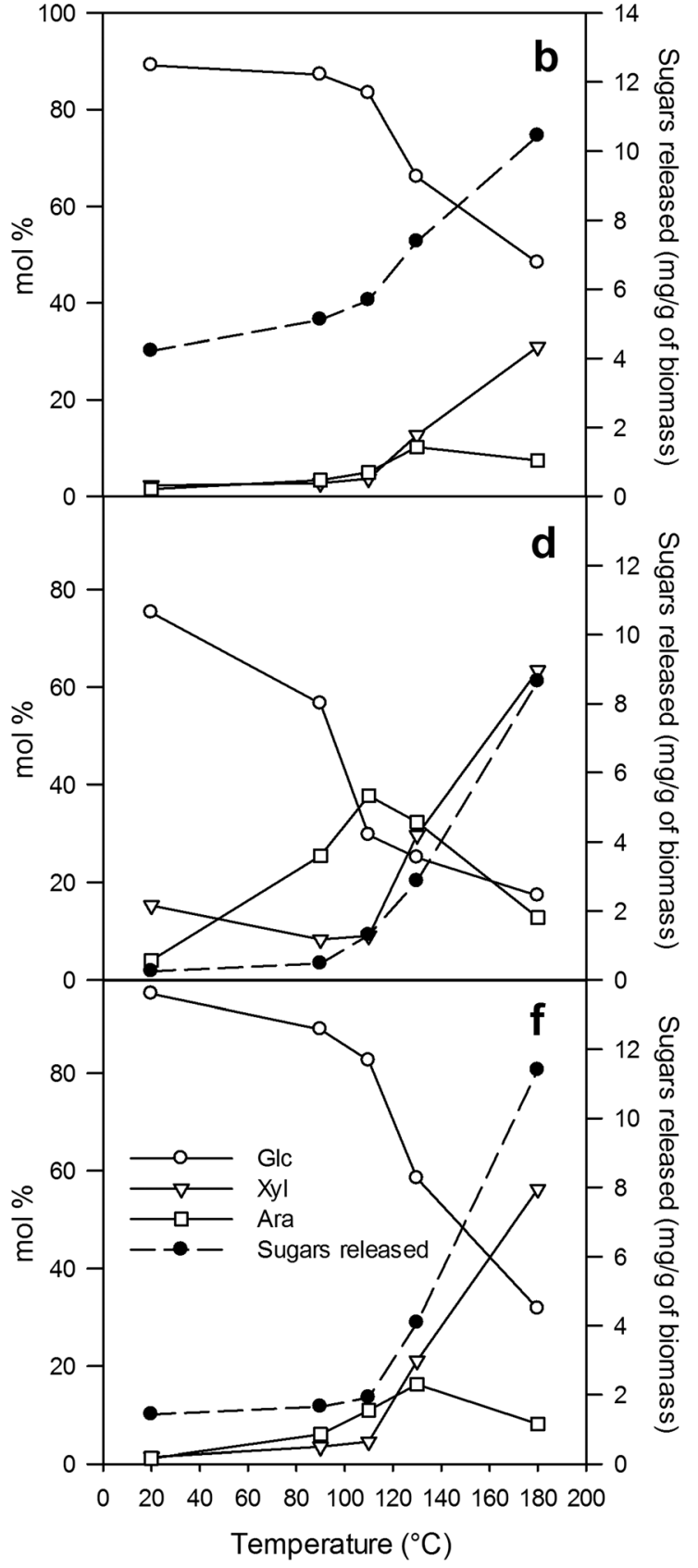

$(\mathbf{a}, \mathbf{b})$, miscanthus $(\mathbf{c}, \mathbf{d})$ or sugarcane bagasse $(\mathbf{e}, \mathbf{f})$ maintained at the indicated temperatures for $30 \mathrm{~min}$. For standard deviations and full monosaccharide composition, see Supplemental Table 1 and 2. The experiments were carried out in triplicates 
the most abundant monosaccharides, with maximal proportion of 89 and $62 \%$ as compared to the total sum of the monosaccharides, respectively (Fig. 1 and Supplemental Tables 1 and 2). In relative abundance, these were followed by arabinose (up to $39 \%$ ), galactose (up to $10 \%$ ) and mannose (up to $6 \%$ ), whereas only traces of galacturonic acid and glucuronic acid were detected (below $2 \%$ ) in most of the samples (Supplemental Tables 1 and 2). However, the relative abundance of these sugars and sugar acids depended on the $\mathrm{pH}$, temperature and feedstock. In general, alkaline conditions released a complex mixture of monosaccharides with a large representation of C5 sugars (Supplemental Tables 1 and 2). Acidic conditions, on the other hand, produced liquors with a higher proportion of glucose, particularly at low temperatures (Supplemental Tables 1 and 2). In addition, the relative abundance of glucose in the liquors decreased with increasing temperatures, mainly due to the relative increase of xylose, under both acid and alkaline conditions (Fig. 1). The relative abundance of arabinose showed a more complex profile: increasing with higher temperatures under alkaline conditions, but showed a maximum at intermediate temperatures under acidic conditions. In terms of feedstock, maize stover produced liquors with glucose as the predominant monosaccharide in both acid and alkaline conditions (Fig. 1). Miscanthus, in turn, presented a more complex monosaccharide profile in all pretreatments (Supplemental Tables 1 and 2). Under alkaline conditions, xylose was the predominant monosaccharide released from pretreated miscanthus (Fig. 1). In contrast, arabinose, galactose, galacturonic acid and glucuronic acid were particularly abundant in acid liquors at 110 and $130{ }^{\circ} \mathrm{C}$ (Supplemental Tables 1 and 2). Sugarcane bagasse pretreatment liquors showed a larger proportion of glucose than those of miscanthus under all pretreatments (Fig. 1). The xylose and arabinose found in pretreatment liquors most likely originated from hydrolysis of xylans, which are the major constituents of grass hemicelluloses and have a backbone chain of $\beta-1,4-$ linked xyloses with mostly arabinose decorations [26]. The glucose could originate from the hydrolysis of glucosecontaining matrix polysaccharides such as the noncrystalline portions of cellulose, $\beta-1,3-$ and $\beta$-1,4-mixed linkage glucans and xyloglucans, although the latter are generally present in low quantities in grass cell walls [27]. In addition, some of the solubilised sugars detected could also originate from other sugar-containing compounds such as starch, glycosylated flavonoids and others. In general, the combined results show that alkaline pretreatment removes polysaccharides from the hemicellulosic fraction with an efficiency that increases with temperature (Supplemental Tables 1 and 2). Acidic pretreatment conditions at lower temperatures $\left(20\right.$ to $\left.90{ }^{\circ} \mathrm{C}\right)$ are less effective in removing the hemicelluloses than are alkaline pretreatments, but the effectiveness increases with the temperature. At the higher temperatures $\left(180^{\circ} \mathrm{C}\right)$, the acidic pretreatment becomes even more effective in removing the hemicelluloses than alkaline pretreatment, and this likely reflects acid hydrolysis of these polymers.

Effects of the Concentration of Acid and Alkaline on Sugar Release at Low and High Temperatures

Once the incremental effects of temperature on the sugar composition of the pretreatment liquor and saccharification hydrolysate of the three feedstocks were established, we performed a study of the effects on the biomass of increasing concentrations of acid and alkali pretreatment at a fixed low or high temperature. The conditions used were water and $0.2,0.4$ and $1 \mathrm{~N}$ of $\mathrm{H}_{2} \mathrm{SO}_{4}$ and $\mathrm{NaOH}$ applied at 20 and $180{ }^{\circ} \mathrm{C}$ to maize stover, miscanthus and sugarcane bagasse for $40 \mathrm{~min}$.

Figures 2 and 3 show the effect of increasing chemical treatment concentration on amount of sugars present in the pretreatment liquor at 20 and $180{ }^{\circ} \mathrm{C}$. The total amount of sugars released in the pretreatment liquor increased with increasing alkaline concentration at both 20 and $180{ }^{\circ} \mathrm{C}$ in each of the three feedstocks (Fig. 2). The effect of increasing acid concentration on the total amount of sugars released in the pretreatment liquor was more complex and depended on the temperature and biomass used (Fig. 3). With miscanthus and sugarcane bagasse as a feedstock, acid pretreatment appeared rather inefficient in releasing sugars from the biomass at $20{ }^{\circ} \mathrm{C}$ for all concentrations tested. Maize stover, in contrast, did release considerable amounts of sugars at $20{ }^{\circ} \mathrm{C}$ that are most likely derived from nonhemicellulosic sugar-containing compounds. At $180{ }^{\circ} \mathrm{C}$, maize stover appeared to quickly reach a maximal level of sugar release under acidic pretreatment conditions; increasing acid concentration above $0.2 \mathrm{~N}$ did not release more sugars into the liquor. In the case of miscanthus and sugarcane bagasse, increasing acid concentration above $0.2 \mathrm{~N}$ had a positive effect on the total amount of sugar released at $180{ }^{\circ} \mathrm{C}$. In terms of the monosaccharide composition of the pretreatment liquor, there was a relative increase in xylose and a relative decrease in glucose with increasing concentrations of $\mathrm{NaOH}$ for the three feedstocks at both 20 and $180{ }^{\circ} \mathrm{C}$ (Fig. 2). With a few exceptions, the monosaccharide composition of the pretreatment liquor was largely similar between the different concentrations of $\mathrm{H}_{2} \mathrm{SO}_{4}$ used, but clearly differed between the different temperatures tested (Fig. 3 and Supplementary Table 4). At $180{ }^{\circ} \mathrm{C}$, the fraction of xylose in the acid pretreatment liquor of maize stover equalled the fraction of glucose in all concentrations tested. On the other hand, xylose was the predominant sugar in both miscanthus and sugarcane bagasse acid pretreatment liquors at $180{ }^{\circ} \mathrm{C}$. 


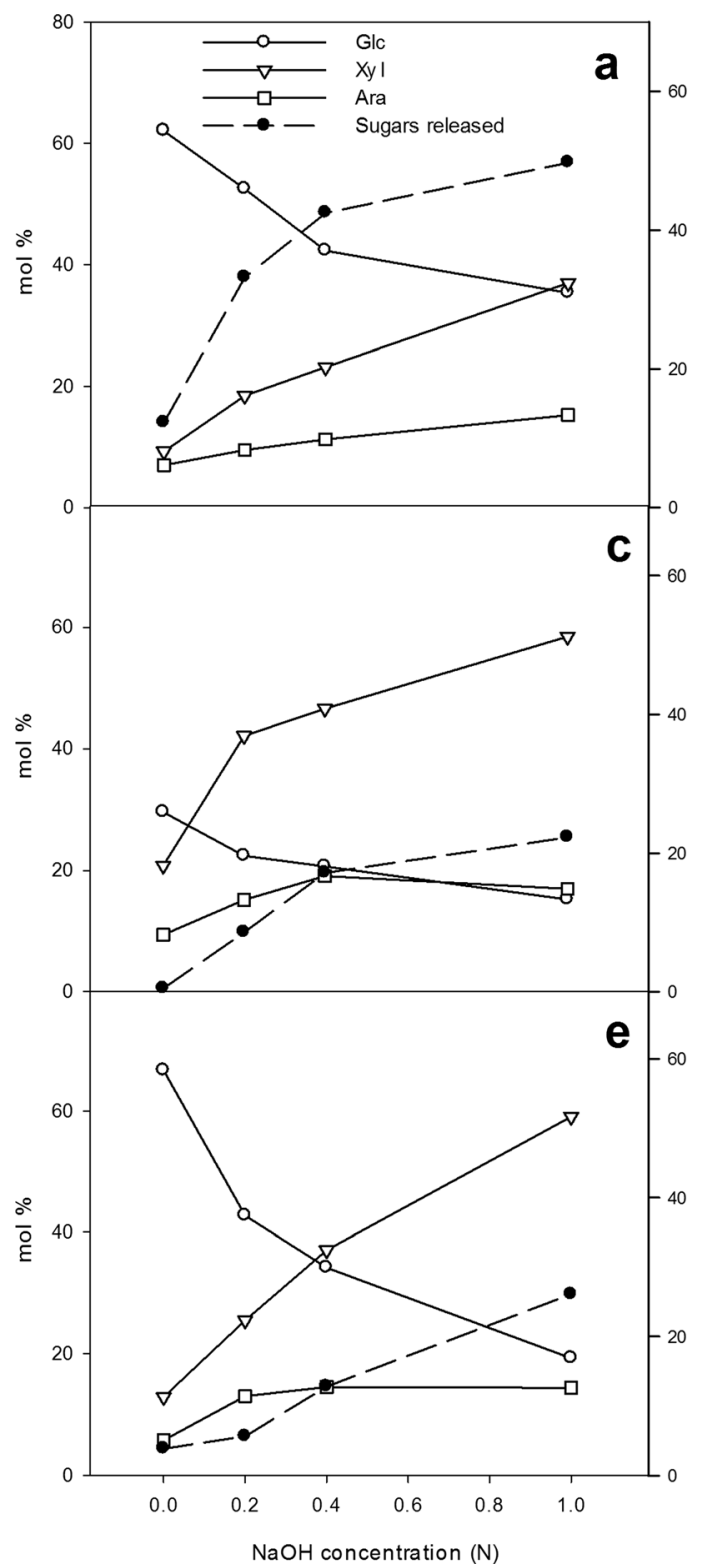

Fig. 2 Amount of sugars released and monosaccharide composition of the pretreatment liquor with increasing concentrations of $\mathrm{NaOH}$. Total sugars released after TFA treatment and $\mathrm{mol} \%$ composition of the TFAreleased monosaccharides from maize stover $(\mathbf{a}, \mathbf{b})$, miscanthus $(\mathbf{c}, \mathbf{d})$ and sugarcane bagasse $(\mathbf{e}, \mathbf{f})$ using increasing concentrations of $\mathrm{NaOH}$ at

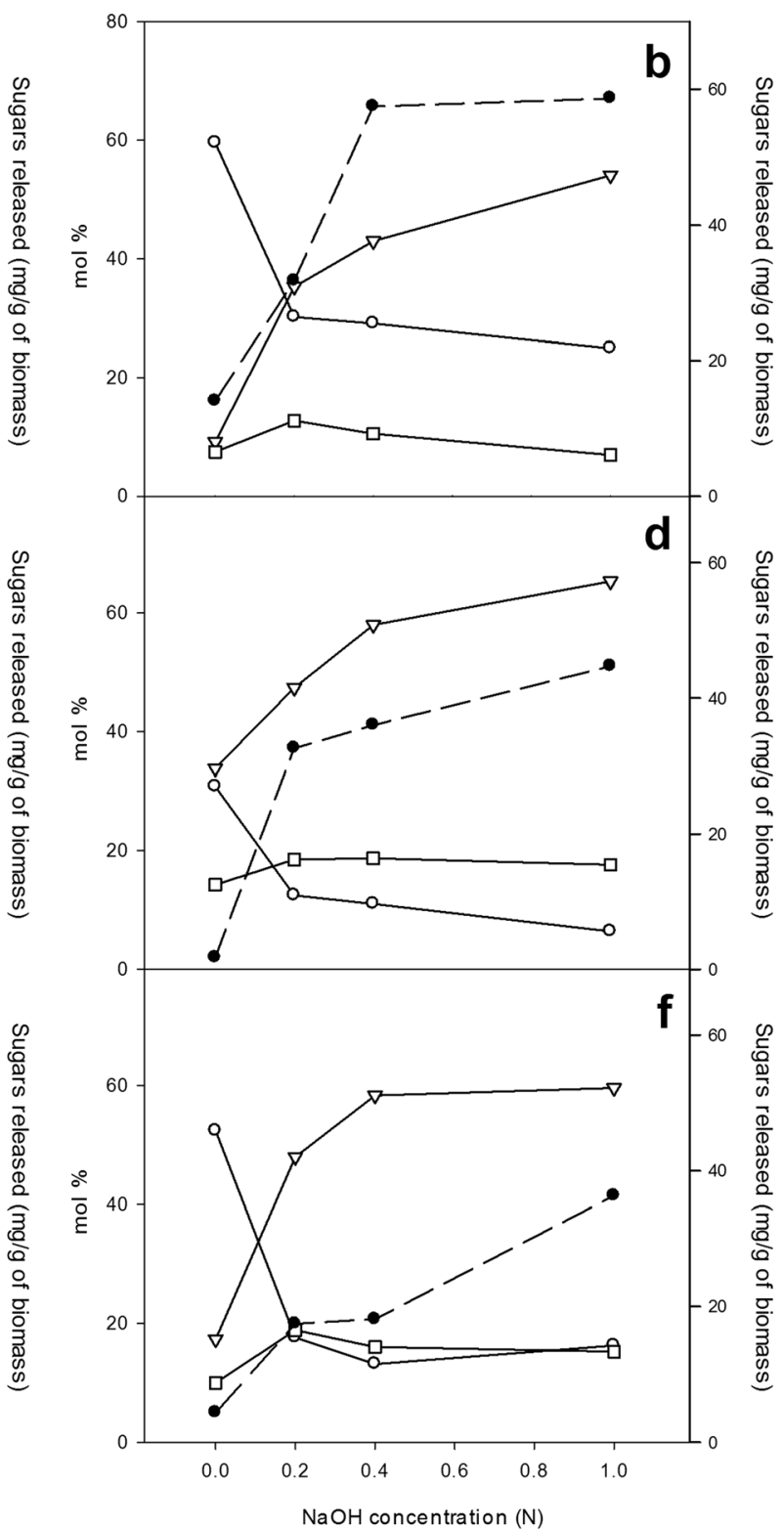

$20^{\circ} \mathrm{C}(\mathbf{a}, \mathbf{c}, \mathbf{e})$ and $180^{\circ} \mathrm{C}(\mathbf{b}, \mathbf{d}, \mathbf{f})$ during $40 \mathrm{~min}$. Sugars were determined by HPAEC after TFA treatment of the respective pretreatment liquors in all three repetitions of the experiment. For standard deviations and full monosaccharide composition, see Supplemental Table 3

pretreated samples. Miscanthus proved to be the most responsive to temperature and chemical treatment in terms of lignin release. Even at $180{ }^{\circ} \mathrm{C}$, acidic pretreament was ineffective at reducing the lignin fraction of the feedstock residue, compared to alkaline. This is in accordance with the observation that acid pretreatment at temperatures above the glass transition temperature of lignin $\left(\sim 130{ }^{\circ} \mathrm{C}\right)$ is able to melt and redistribute lignin in the cell wall, but not to remove lignin from the biomass [28]. 


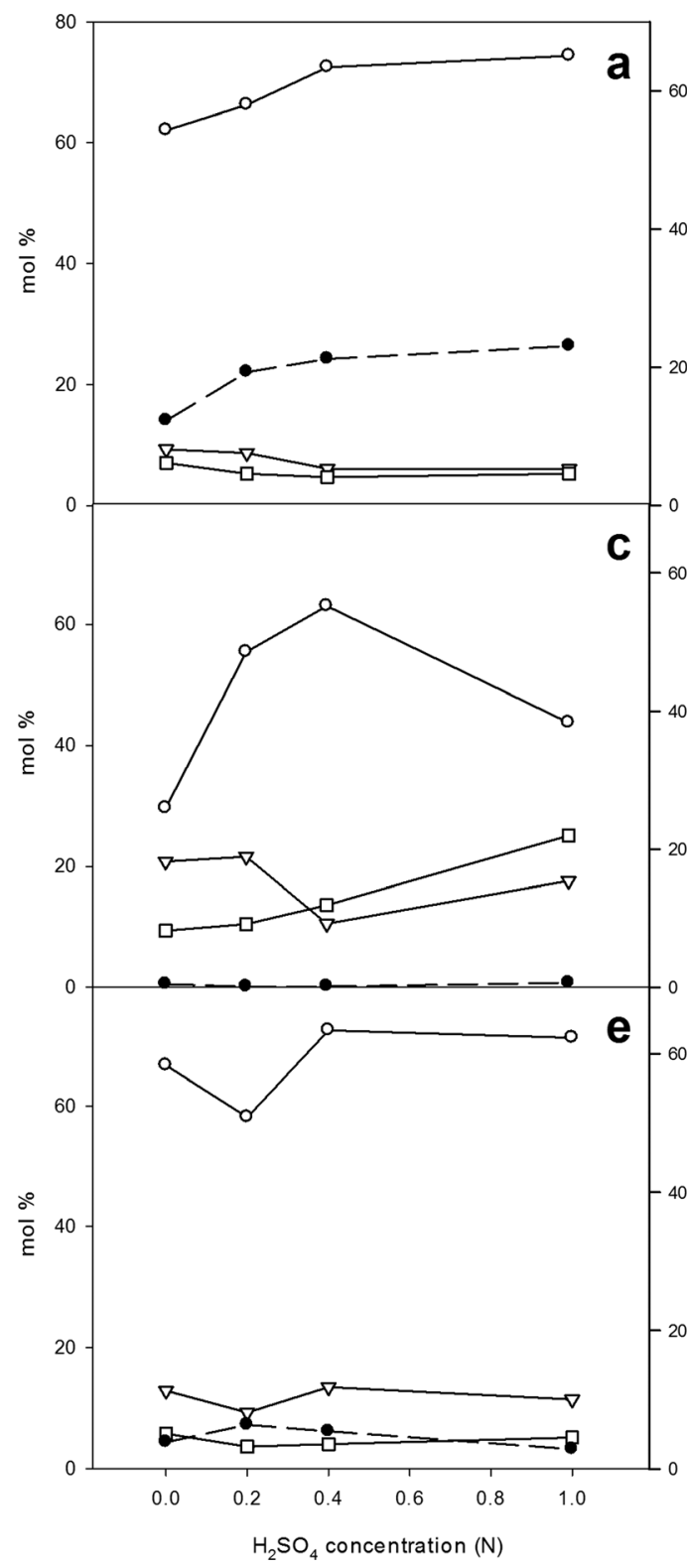

Fig. 3 Amount of sugars released and monosaccharide composition of the pretreatment liquor with increasing concentrations of $\mathrm{H}_{2} \mathrm{SO}_{4}$. Total sugars released after TFA treatment and mol\% composition of the TFAreleased monosaccharides from maize stover $(\mathbf{a}, \mathbf{b})$, miscanthus $(\mathbf{c}, \mathbf{d})$ and sugarcane bagasse $(\mathbf{e}, \mathbf{f})$ using increasing concentrations of $\mathrm{H}_{2} \mathrm{SO}_{4}$ at

Effects of Pretreatments on the Release of Phenolics and Fatty Acids

To avoid column and detector saturation, a relatively small portion of the alkaline pretreatment liquors (corresponding to about $80 \mu \mathrm{L}$ of the initial pretreatment liquor) was used for UHPLC-MS analysis. Because column and detector saturation was less of an issue for the pretreatment liquors of water and acid-treated samples, a larger portion of the sample (corresponding to $320 \mu \mathrm{L}$ of the initial pretreatment liquor) was

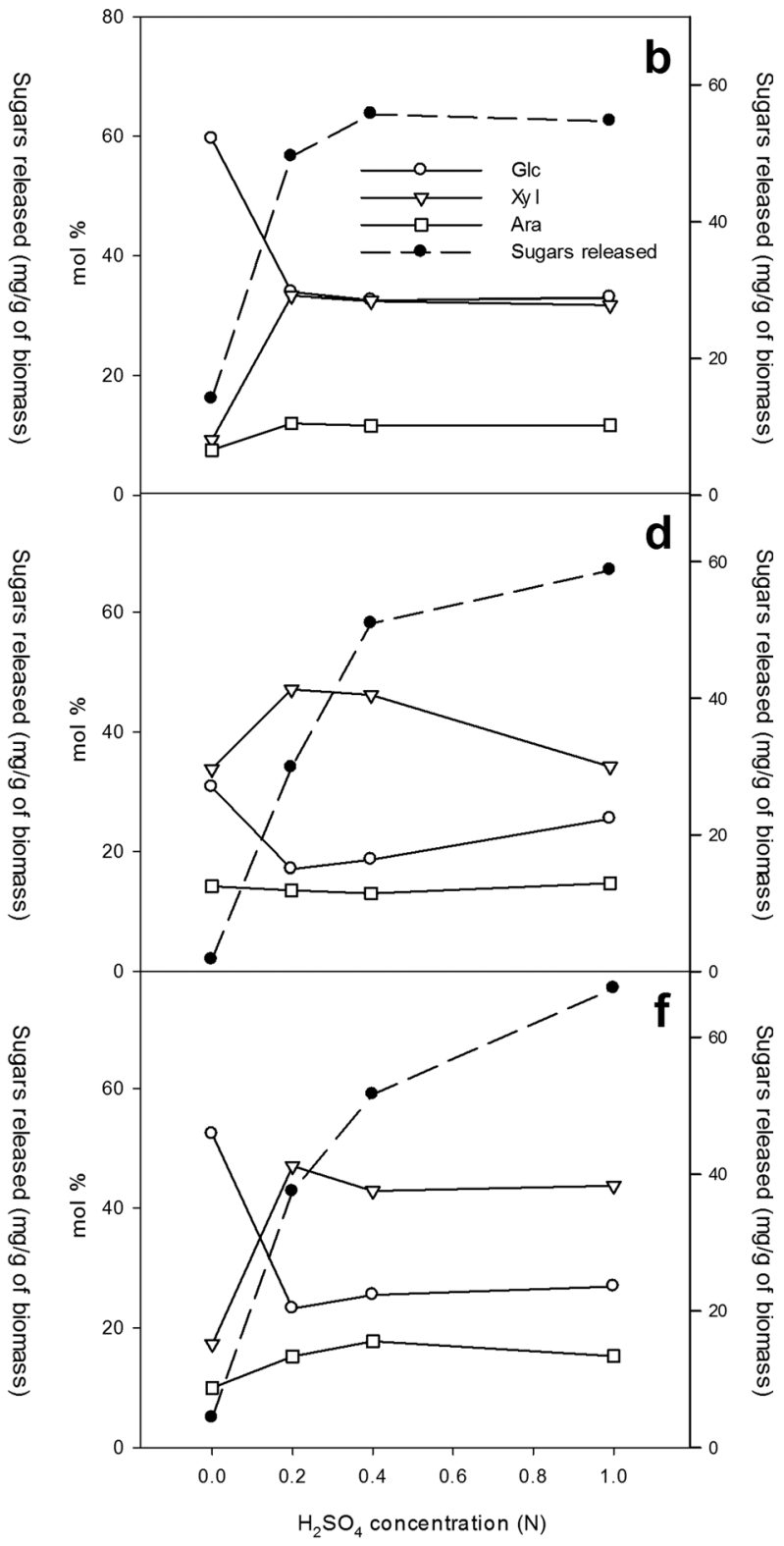

$20^{\circ} \mathrm{C}(\mathbf{a}, \mathbf{c}, \mathbf{e})$ and $180^{\circ} \mathrm{C}(\mathbf{b}, \mathbf{d}, \mathbf{f})$ during $40 \mathrm{~min}$. Sugars were determined by HPAEC after TFA treatment of the respective pretreatment liquors in all three repetitions of the experiment. For standard deviations and full monosaccharide composition, see Supplemental Table 4

used for UHPLC-MS analysis in this case. Comparison of the total ion current of UHPLC-MS chromatograms of the pretreatment liquor of alkaline and acid-treated samples revealed that alkaline pretreated samples were indeed richer in molecules as compared to acid pretreated samples with the same molarity and temperature (Supplementary Fig. 1).

To make a general comparison between the pretreatment conditions (in terms of concentration, temperature and feedstock), all data were integrated and aligned after which PCA 
Fig. 4 Remnant lignin in feedstock residue after chemical pretreatment. Percentage of acetyl bromide soluble lignin (ABSL) as expressed to the total insoluble residue $(w / w)$ after pretreatment for $40 \mathrm{~min}$ at 20 and $180{ }^{\circ} \mathrm{C}$ of maize stover (a), miscanthus (b) and sugarcane bagasse (c) at increasing concentrations of $\mathrm{NaOH}$ or $\mathrm{H}_{2} \mathrm{SO}_{4}$ at 20 and $180{ }^{\circ} \mathrm{C}$

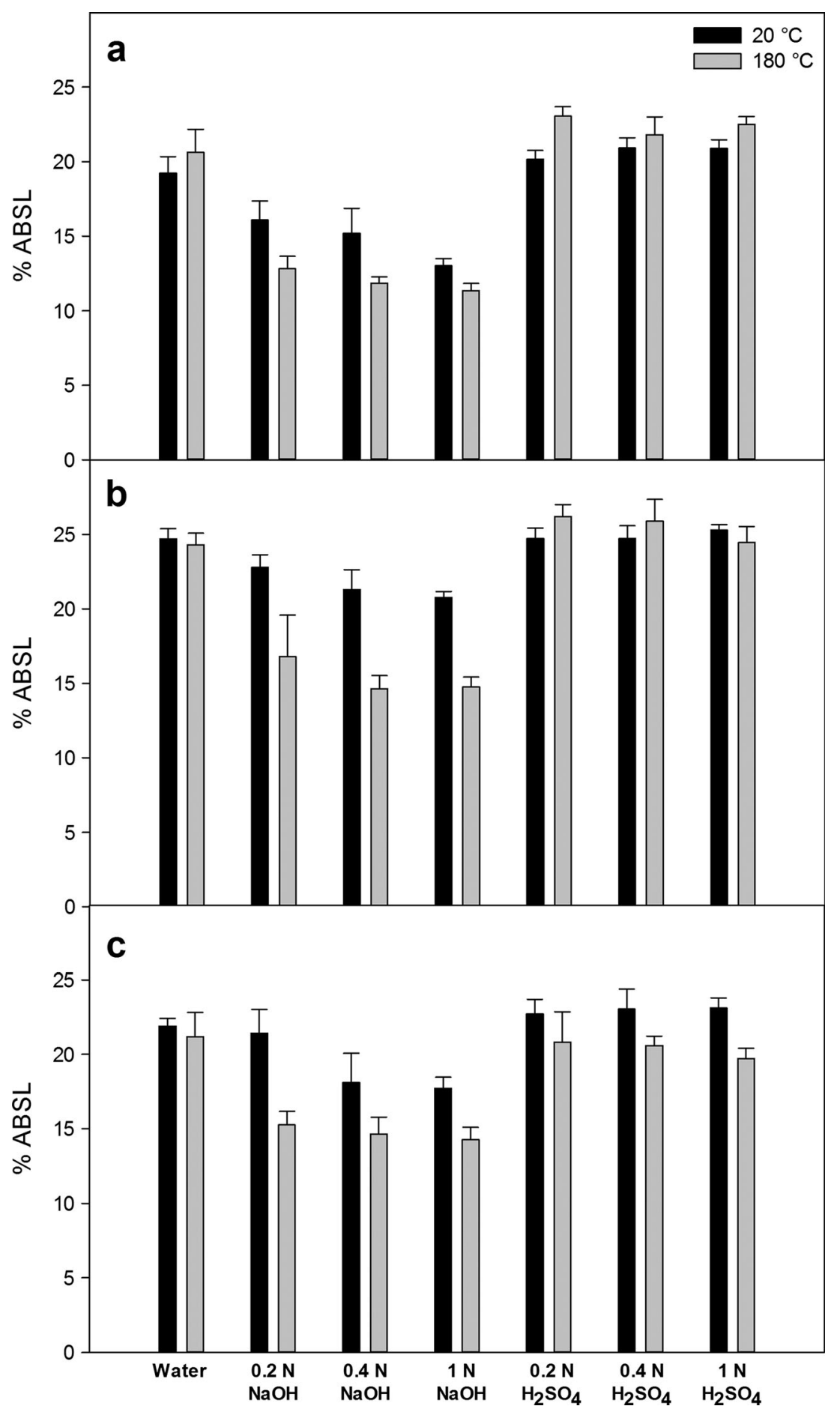

was performed (Supplementary Fig 2). Because of the large compositional differences between acid and alkaline samples and due to the different dilutions used for these two types of samples, PCA was performed on alkaline and acid pretreated samples separately. From the PCA plots, it can be deduced that the influence of temperature on the composition of water pretreated liquors was modest. In addition, it was clear that the composition of the pretreatment liquor with acid at $20{ }^{\circ} \mathrm{C}$ was not very different from water pretreatment, but the pretreatment liquor with acid at $180^{\circ} \mathrm{C}$ was clearly different, indicating that the acid pretreatment needs higher temperatures to be effective in releasing compounds from the biomass compared to alkali treatments. In terms of the biomass, the PCA plots showed a high similarity between miscanthus and sugarcane bagasse, while maize stover samples were clearly different. 
Fig. 5 Compounds structurally characterised in alkaline $(1-21)$ and acid pretreatment liquors (22-29). See Supplemental Fig. 2 for their structural characterisation
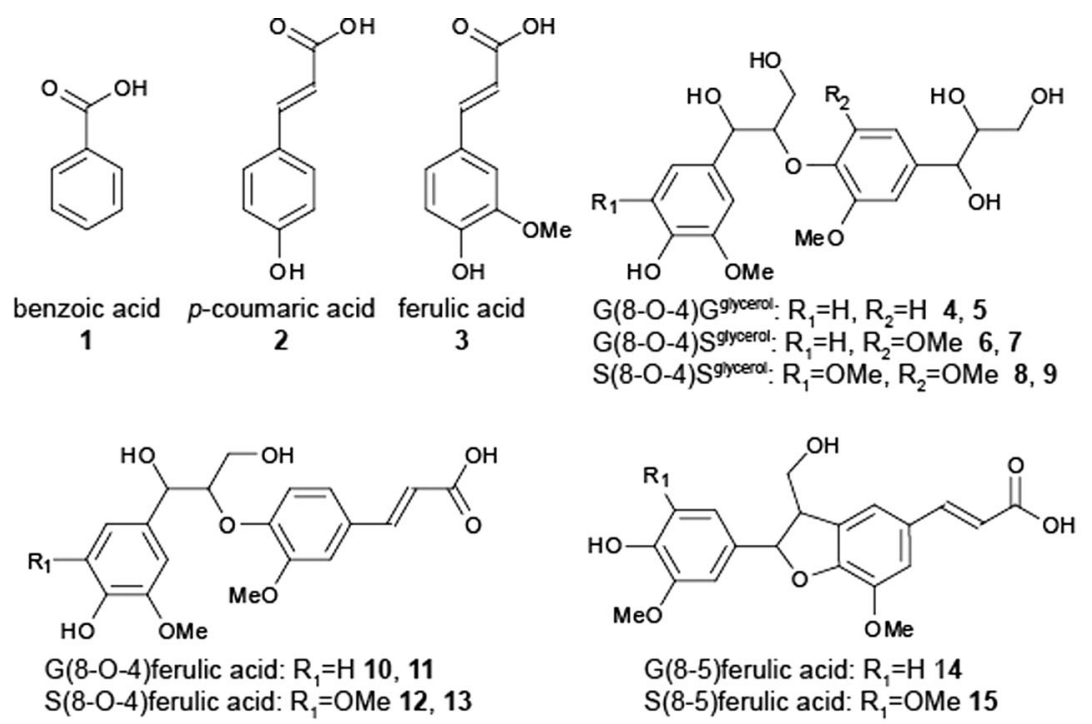<smiles>COc1ccc(C=C(C(=O)O)C(=O)O)cc1OC</smiles>

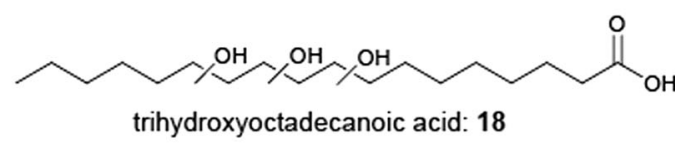<smiles>CCCCCCC(O)CC(O)C=CCCCCCCC(=O)O</smiles>

ferulic acid(8-8)ferulic acid: 16,17<smiles>[R2]OC(=O)/C=C/c1ccc(O)c([R7])c1</smiles>

p-coumaroyl pentose: $\mathrm{R}_{1}=\mathrm{H}, \mathrm{R}_{2}=$ pentose $22,23,24$ feruloyl pentose: $R_{1}=O M e, R_{2}=$ pentose $25,26,27,28$ feruloyl quinic acid: $R_{1}=O M e, R_{2}=$ quinic acid 29

Twenty-one compounds that were present in the alkaline pretreatment liquor could be structurally characterised based on their MS/MS fragmentation (Fig. 5, Supplemental Fig. 3). Their respective ion traces were manually integrated in each of the chromatograms (Table 2). $p$-Hydroxybenzaldehyde, $p$ coumaric acid and ferulic acid were among the highest accumulating compounds, based on MS traces. This class of 'aromatic monomers' was detected both at 20 and $180{ }^{\circ} \mathrm{C}$ and in all concentrations of $\mathrm{NaOH}$ used. In general, the concentration of $p$-coumaric acid increased both with increasing temperature and increasing $\mathrm{NaOH}$ concentration, whereas the concentration of $p$-hydroxybenzaldehyde was only influenced by temperature (and not by $\mathrm{NaOH}$ concentration) and the concentration of ferulic acid was only influenced by $\mathrm{NaOH}$ concentration (and not by temperature) (Table 2). In terms of feedstock, $p$-hydroxybenzaldehyde and $p$-coumaric acid had the highest concentrations in pretreatment liquors from sugarcane bagasse, followed by that of miscanthus and the lowest concentrations were found in pretreatment liquors of maize stover samples. Ferulic acid had also the highest concentrations in sugarcane bagasse liquors but had similar concentrations in miscanthus and maize stover samples. Interestingly, much smaller amounts of these free aromatic monomers were found in acid pretreated samples (not shown). In addition, a series of phenylpropanoid dimers present in the alkaline pretreatment liquor could be structurally characterised. These dimers can be classified in two classes: dimers with a glycerol aliphatic chain and ferulic acid containing dimers (Fig. 5, Table 2). The dimers with a glycerol aliphatic chain might arise from cleavage from beta aryl ethers in hot alkaline conditions [29-32]. The occurrence of these dimers in $20{ }^{\circ} \mathrm{C}$ samples hints that lignin degradation is occurring at these relatively low temperatures. However, it cannot be excluded that the dimers in $20^{\circ} \mathrm{C}$ samples originate 
Table 2 Abundance of the compounds characterised in alkaline pretreatment liquors

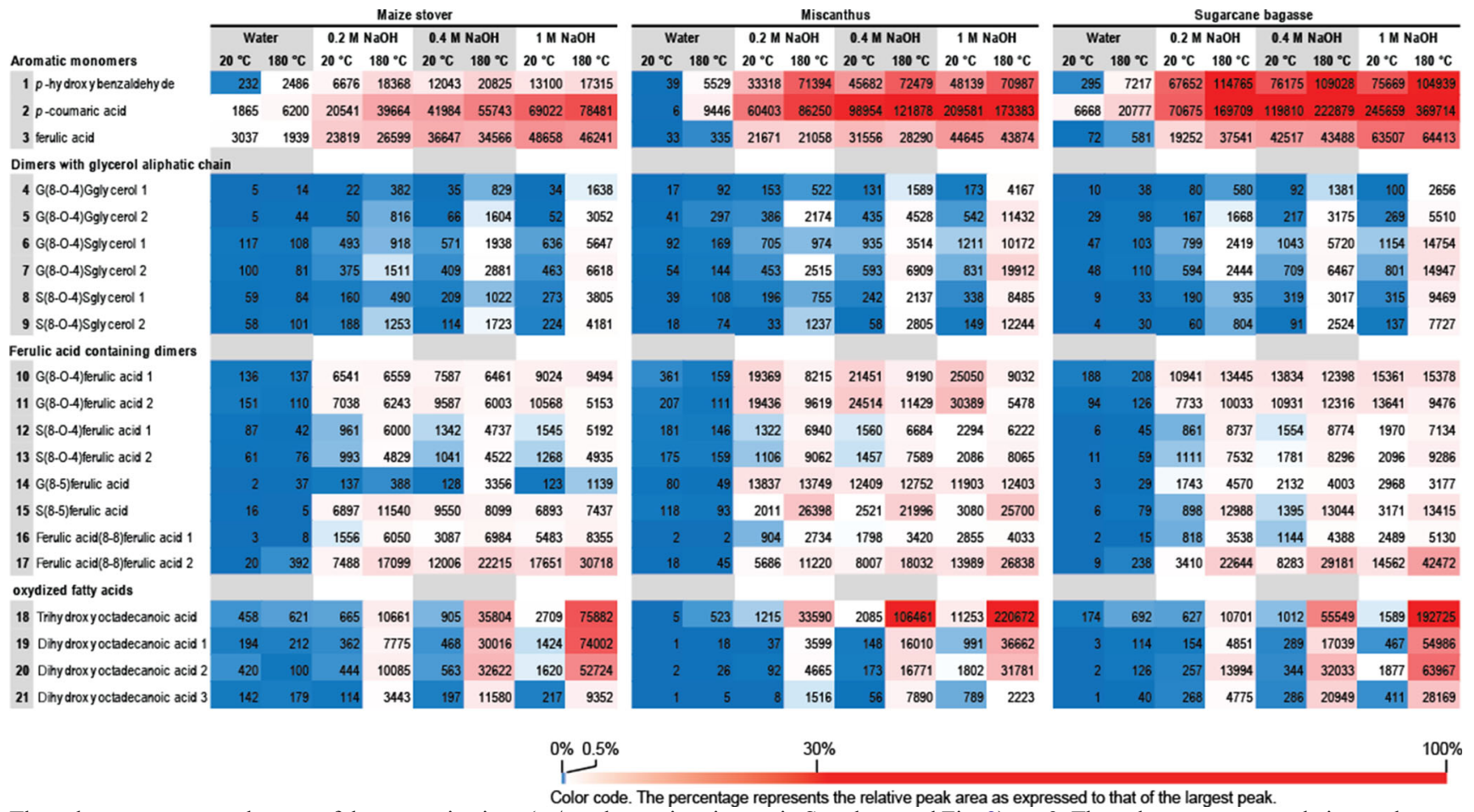

The values represent peak areas of the respective ions $(m / z$ and retention time as in Supplemental Fig. 2$), n=3$. The colours represent relative peak areas with red and blue for the largest and smallest peak area, respectively, as indicated in the colour code

from compounds other than polymeric lignin. In this respect, it is important to note that a glycerol-type trimer, G(8-O-4)S(8$5) \mathrm{G}^{\text {glycerol }}$ has been found in xylem extracts of poplar [33]. S(8-O-4)ferulic acids and S(8-5)ferulic acid were found in the alkaline pretreatment liquors of all feedstocks tested. In general, these phenolic compounds were mainly present in the $180{ }^{\circ} \mathrm{C}$ pretreatment liquors and lower in the $20^{\circ} \mathrm{C}$ liquors (Table 2). Interestingly, G(8-O-4)ferulic acids and $\mathrm{G}(8$ 5)ferulic acid showed not the same response as their $\mathrm{S}$ unit containing homologues. Strikingly, G(8-O-4)ferulic acids were mainly present in $20{ }^{\circ} \mathrm{C}$ pretreated liquors and were lower in the $180{ }^{\circ} \mathrm{C}$ liquors of miscanthus (Table 2). These differences in accumulation indicate that G- and S-derived compounds have different depolymerisation properties and/ or that the released fragments have different re-polymerisation or degradation properties.

Ferulic acid(8-8)ferulic acid dimers were detected in all alkaline pretreatment liquors, and their concentration increased with increasing chemical load and temperature. The presence of ferulic acid dimers in alkaline extracts of grass cell wall material has previously been described [34].

A fourth class of compounds detected in alkaline pretreatment liquors were oxidised C18 fatty acids (Fig. 5, Table 2, Supplemental Fig. 3). These compounds might derive from the fatty acid moieties of phospholipids, triglycerides and waxes. Unsaturated C18 fatty acid moieties in these metabolites are relatively abundant in sugarcane and other grasses [35-37]. In alkaline conditions, the phospholipids, triglycerides and waxes will first be hydrolysed, and after which, the unsaturated fatty acid moiety can further be oxidised by $\mathrm{O}_{2}$ via radical reactions [38]. Based on MS intensity, the trihydroxyoctadecanoic acid is a dominant peak in the samples pretreated with $1 \mathrm{~N} \mathrm{NaOH}$ at $180^{\circ} \mathrm{C}$. In these samples, the peak area equalled or exceeded that of $p$-coumaric acid. Its abundance was positively correlated with the concentration of $\mathrm{NaOH}$. In addition, relatively low amounts of oxidised fatty acids were detected in the samples pretreated at $20^{\circ} \mathrm{C}$. This observation is in line with the hypothesis that these compounds are derived from oxidation of unsaturated $\mathrm{C} 18$ fatty acids by $\mathrm{O}_{2}$, a reaction that is enhanced at higher temperatures [38].

Also, the highest accumulating compounds (based on MS ion traces) in acid pretreatment liquors could be tentatively structurally characterised. All were $p$-coumarate and ferulate esters (Table 3, Supplemental Fig. 3). Their respective ion traces were manually integrated in each of the chromatograms of the acid pretreatment liquors, as these compounds could not be detected with certainty in alkaline pretreatment liquors (Table 3). Interestingly, both $p$-coumaroyl and feruloyl pentoses were found in any of the $180{ }^{\circ} \mathrm{C}$ acid pretreatment liquors but not in those of $20^{\circ} \mathrm{C}$. These compounds could 
Table 3 Abundance of the compounds characterised in acid pretreatment liquors. The values represent peak areas of the respective ions $(\mathrm{m} / \mathrm{z}$ and retention time as in Supplemental Fig. 2), $n=3$. The colours represent relative peak areas with red and blue for the largest and smallest peak area, respectively, as indicated in the colour code
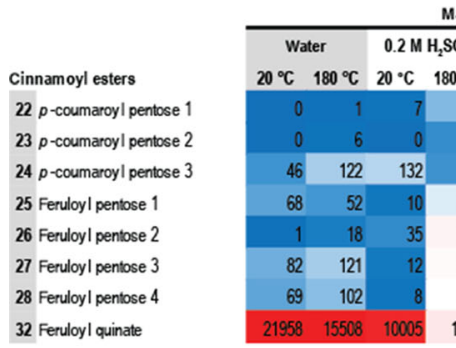

Maize stover

Miscanthus
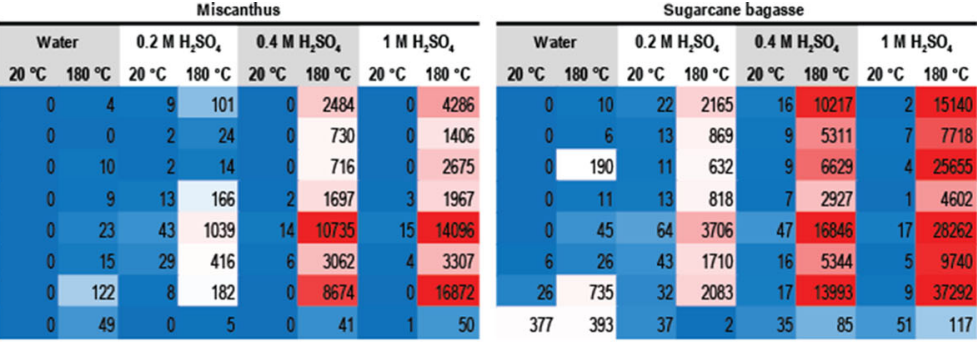

\begin{tabular}{l|llll}
1264 & 10484 & 5702 & 6382 & 12325 \\
\hline
\end{tabular}

$0 \% 0.5 \%$

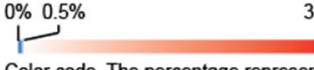

$30 \%$

Color code. The percentage represents the relative peak area as expressed to that of the largest peak.

logically be derived from the degradation of hemicelluloses, as acid conditions at higher temperatures are able to degrade the glycosidic bonds in hemicellulose [39], but not the ester bond that link the $p$-coumarates and ferulates to hemicellulose. In addition, feruloyl quinate was found in the water extracts of the maize stover samples. Although there were some subtle differences in the concentrations of feruloyl quinate in the pretreatment liquor depending on the concentration of $\mathrm{H}_{2} \mathrm{SO}_{4}$ and temperature used, this compound remained largely unaffected during acid pretreatment.

Generation of Furfural and Hydroxymethyl Furfural During Pretreatment

Furfural and hydroxymethyl furfural (HMF) are dehydration products of pentose and hexose sugars, respectively, and are well-known inhibitors of fermentation, but could also serve as industrial platform chemicals $[40,41]$ and thus may be problematic or valuable depending on whether or not the pretreatment liquor is further processed. Significant amounts of either HMF or furfural were only detected using acid pretreatment at $180{ }^{\circ} \mathrm{C}$ (Fig. 6). The amounts of $\mathrm{HMF}$ and furfural in pretreatment liquors were feedstock dependent, with maize stover producing more HMF than either miscanthus or sugarcane bagasse; furfural was produced in higher quantities from miscanthus and sugarcane bagasse feedstock as compared to maize stover. Miscanthus pretreatment liquor contained relatively low amounts of HMF as compared to the amounts of furfural. The difference in HMF and furfural production reflects the monosaccharide composition released into the pretreatment liquor by the different feedstocks. Maize released a greater proportion of hexoses into the pretreatment liquor than miscanthus and sugarcane bagasse (Fig. 6) and hence also produced more HMF.

\section{Discussion}

Improving the profitability of lignocellulosic biofuel production is critical to its commercial development. In this paper, we have examined the types and quantities of products released from lignocellulosic feedstocks under a range of aqueous pretreatment conditions in order to identify conditions that both satisfy the need to potentiate enzymatic hydrolysis, as well as releasing potentially valuable coproducts. Alkaline pretreatments provide a range of potentially interesting chemical building blocks in the pretreatment liquors. In addition, the potential to use the sugars produced during alkaline pretreatments for fermentation is higher as less inhibitory substances such as HMF and furfural are produced as compared to acid pretreatments (Fig. 6). The amount of lignin remaining in the biomass is lower when $\mathrm{NaOH}$ is used during pretreatment (and not by use of $\mathrm{H}_{2} \mathrm{SO}_{4}$ ) and a temperature of $180{ }^{\circ} \mathrm{C}$ is more effective than $20^{\circ} \mathrm{C}$ (Fig. 4). In addition, while at $20^{\circ} \mathrm{C}$ there is a positive relation between chemical load and lignin removal, the chemical load does not seem to influence the remaining lignin at $180^{\circ} \mathrm{C}$ (Fig. 4). The lower the temperature and the lower the chemical load during pretreatment that needs to be used to achieve an efficient saccharification, the more cost-effective the whole biorefinery process will be. Thus, according to our data, there is no need to go to higher temperatures than $130{ }^{\circ} \mathrm{C}$ and chemical concentration higher than $0.2 \mathrm{~N}$ when saccharification yield is the main interest.

In terms of added-value chemical compounds released during these pretreatment conditions, $\mathrm{NaOH}(0.2 \mathrm{~N}$ at $130{ }^{\circ} \mathrm{C}$ ) releases similar amounts of sugars as compared to $\mathrm{H}_{2} \mathrm{SO}_{4}$, although there are some differences between the different feedstocks tested (Fig. 1 Supplementary Tables 1 
Fig. 6 Hydroxymethyl furfural (a) and furfural (b) production under increasing strength of chemical pretreatment at 20 and $180^{\circ} \mathrm{C}$ during $40 \mathrm{~min}$. The experiments were conducted in triplicates

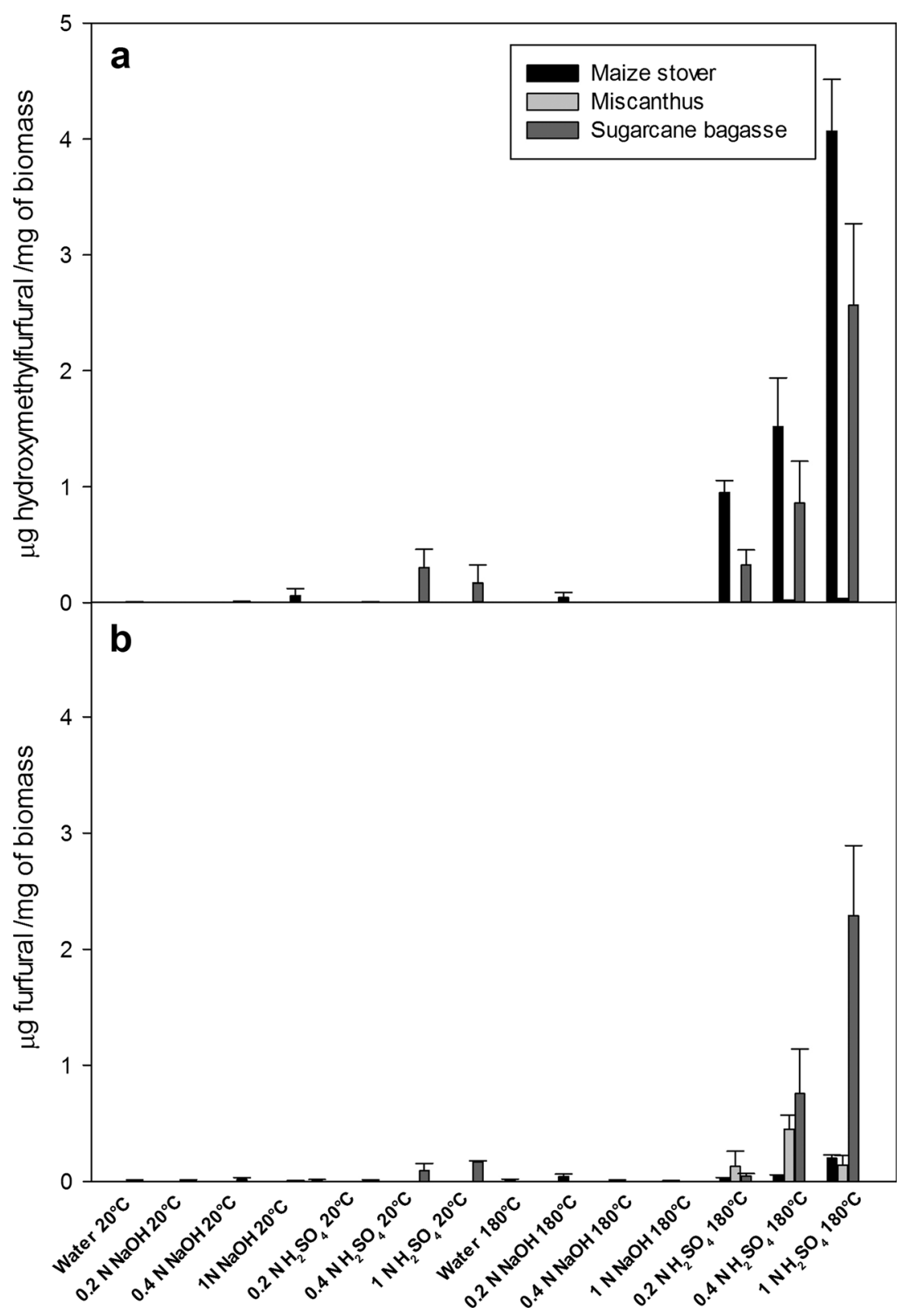

and 2). In general, the pretreatment liquor is more enriched in pentose sugars (and the remaining cell wall material enriched in hexoses) when $\mathrm{NaOH}$ is used as compared to $\mathrm{H}_{2} \mathrm{SO}_{4}$. This might be favourable as these sugars could be used in fermentation with yeasts optimised to use pentose sugars [42] or pentose-fermenting organisms such as Geobacillus [43] or by filamentous fungi for enzyme production [44] or used in anaerobic digesters to produce methane for bioenergy applications. In addition to sugars, other potentially useful chemical building blocks present in the alkaline pretreatment liquors were characterised. A series of dimers with a glycerol aliphatic chain that are derived from lignin degradation were found after alkaline pretreatment at $180^{\circ} \mathrm{C}$ and not at $20^{\circ} \mathrm{C}$ (Tables 2 and 3). Similarly, ferulic acid containing dimers are more abundant at higher temperatures (with the exception of two G(8-O-4)ferulic acid dimers). However, the quantity of these products remained relatively low and it is questionable if they can be purified for further processing as technologies involving isolation of aromatic building blocks from biomass are still in their infancy [45]. However, recent developments in purification of phenolics via adsorption techniques look promising [46]. On the other hand, the mixture of these phenolic dimers might have a significant value in itself for the chemical industry.

In terms of yield, $p$-hydroxybenzaldehyde, $p$-coumaric acid and ferulic acid seem efficiently released by $\mathrm{NaOH}$ even at low temperatures and low chemical load (Table 2). The actual yield of these compounds was not determined in our study but 
will be part of future research. Nevertheless, from a biorefinery perspective, these compounds are potentially of interest as there is a market for these products. For instance, ferulic acid is widely used in the food and cosmetic industries: It is used as the raw material for the production of vanillin and preservatives, as a cross-linking agent for the preparation of food gels and edible films and as an ingredient in sports foods and skin protection agents [47]. Ferulic acid can also be biocatalytically converted into other useful aromatic chemicals including vanillin, styrene and vinylguaiacol [48]. In addition, fatty acids were found in the alkaline pretreatment liquors (Fig. 5, Table 2). In theory, these fatty acids could be readily skimmed as sodium soap from the complex pretreatment liquor prior $\mathrm{pH}$ neutralisation, in a similar manner to that of tall oil being isolated during the kraft pulp process of coniferous wood [49]. The resulting soap has several potential applications, among which the esterification of the fatty acids with methanol or ethanol would produce fatty acid methyl or ethyl esters, respectively, which is biodiesel [49-51].

Acknowledgments The authors thank Bart Ivens for technical support. We would also like to thank Valeria Gazda and Tony Larson for their help in measuring furfural and HMF. We gratefully acknowledge funding through the European Commission's Directorate-General for Research within the 7th Framework Program (FP7/2007-2013) under the grant agreement no. 251132 (SUNLIBB), the Hercules program of Ghent University for the Synapt Q-Tof (grant no. AUGE/014), the 'Bijzonder Onderzoeksfonds-Zware Apparatuur' of Ghent University for the FTICR-MS instrument (174PZA05) and the Multidisciplinary Research Partnership 'Biotechnology for a Sustainable Economy' (01MRB510W) of Ghent University. RV is indebted to the Research Foundation-Flanders for a postdoctoral fellowship.

Open Access This article is distributed under the terms of the Creative Commons Attribution License which permits any use, distribution, and reproduction in any medium, provided the original author(s) and the source are credited.

\section{References}

1. Lima MA, Lavorente GB, da Silva HK, Bragatto J, Rezende CA, Bernardinelli OD, Deazevedo ER, Gomez LD, McQueen-Mason SJ, Labate CA, Polikarpov I (2013) Effects of pretreatment on morphology, chemical composition and enzymatic digestibility of eucalyptus bark: a potentially valuable source of fermentable sugars for biofuel production — part 1. Biotechnol Biofuels 6(1):75. doi:10.1186/17546834-6-75

2. Silverstein RA, Chen Y, Sharma-Shivappa RR, Boyette MD, Osborne J (2007) A comparison of chemical pretreatment methods for improving saccharification of cotton stalks. Bioresour Technol 98(16):3000-3011. doi:10.1016/j.biortech.2006.10.022

3. Prior B, Day D (2008) Hydrolysis of ammonia-pretreated sugar cane bagasse with cellulase, $\beta$-glucosidase, and hemicellulase preparations. Appl Biochem Biotechnol 146(1-3):151-164. doi:10.1007/ s12010-007-8084-0
4. Lora J, Glasser W (2002) Recent industrial applications of lignin: a sustainable alternative to nonrenewable materials. J Polym Environ 10(1-2):39-48. doi:10.1023/a:1021070006895

5. Heaton EA, Flavell RB, Mascia PN, Thomas SR, Dohleman FG, Long SP (2008) Herbaceous energy crop development: recent progress and future prospects. Curr Opin Biotechnol 19(3):202-209. doi:10.1016/j.copbio.2008.05.001

6. Weijde T, Alvim Kamei CL, Torres AF, Vermerris W, Dolstra O, Visser RGF, Trindade LM (2013) The potential of C4 grasses for cellulosic biofuel production. Front Plant Sci 4. doi:10.3389/fpls. 2013.00107

7. Torney F, Moeller L, Scarpa A, Wang K (2007) Genetic engineering approaches to improve bioethanol production from maize. Curr Opin Biotechnol 18(3):193-199. doi:10.1016/j.copbio.2007.03.006

8. Waclawovsky AJ, Sato PM, Lembke CG, Moore PH, Souza GM (2010) Sugarcane for bioenergy production: an assessment of yield and regulation of sucrose content. Plant Biotechnol J 8(3):263-276. doi:10.1111/j.1467-7652.2009.00491.x

9. Clifton-Brown JC, Breuer J, Jones MB (2007) Carbon mitigation by the energy crop, Miscanthus. Glob Chang Biol 13(11):2296-2307. doi:10.1111/j.1365-2486.2007.01438.x

10. Mosier N, Wyman C, Dale B, Elander R, Lee YY, Holtzapple M, Ladisch M (2005) Features of promising technologies for pretreatment of lignocellulosic biomass. Bioresour Technol 96(6):673-686. doi:10.1016/j.biortech.2004.06.025

11. Yang B, Wyman CE (2008) Pretreatment: the key to unlocking lowcost cellulosic ethanol. Biofuels Bioprod Biorefin 2(1):26-40. doi:10. 1002/bbb.49

12. Galbe M, Zacchi G (2012) Pretreatment: the key to efficient utilization of lignocellulosic materials. Biomass Bioenergy 46:70-78. doi: 10.1016/j.biombioe.2012.03.026

13. Clark JH, Luque R, Matharu AS (2012) Green chemistry, biofuels, and biorefinery. Annu Rev Chem Biomol Eng 3:183-207. doi:10. 1146/annurev-chembioeng-062011-081014

14. Goering H, Van Soest PJ (1970) Forage fiber analyses (apparatus, reagents, procedures, and some applications). US Agricultural Research Service, Washington, 379

15. Jones L, Milne JL, Ashford D, McQueen-Mason SJ (2003) Cell wall arabinan is essential for guard cell function. Proc Natl Acad Sci U S A 100(20):11783-11788. doi:10.1073/pnas. 1832434100

16. Fukushima RS, Hatfield RD (2001) Extraction and isolation of lignin for utilization as a standard to determine lignin concentration using the acetyl bromide spectrophotometric method. J Agric Food Chem 49(7):3133-3139. doi:10.1021/jf010449r

17. Hatfield R, Fukushima RS (2005) Can lignin be accurately measured? This paper was originally presented at the Lignin and Forage Digestibility Symposium, 2003 CSSA Annual Meeting, Denver, CO. Crop Sci 45(3):832-839. doi:10.2135/cropsci2004. 0238

18. Jourdes M, Cardenas CL, Laskar DD, Moinuddin SGA, Davin LB, Lewis NG (2007) Plant cell walls are enfeebled when attempting to preserve native lignin configuration with poly-p-hydroxycinnamaldehydes: evolutionary implications. Phytochemistry 68(14):1932-1956. doi:10.1016/j. phytochem.2007.03.044

19. Voelker SL, Lachenbruch B, Meinzer FC, Jourdes M, Ki C, Patten AM, Davin LB, Lewis NG, Tuskan GA, Gunter L, Decker SR, Selig MJ, Sykes R, Himmel ME, Kitin P, Shevchenko O, Strauss SH (2010) Antisense down-regulation of 4CL expression alters lignification, tree growth, and saccharification potential of field-grown poplar. Plant Physiol 154(2):874-886. doi:10.1104/pp. 110.159269

20. Hatfield RD, Grabber J, Ralph J, Brei K (1999) Using the acetyl bromide assay to determine lignin concentrations in herbaceous plants: some cautionary notes. J Agric Food Chem 47(2):628-632

21. Masarin F, Gurpilhares D, Baffa D, Barbosa M, Carvalho W, Ferraz A, Milagres A (2011) Chemical composition and enzymatic 
digestibility of sugarcane clones selected for varied lignin content. Biotechnol Biofuels 4(1):55

22. Torres AF, van der Weijde T, Dolstra O, Visser RGF, Trindade LM (2013) Effect of maize biomass composition on the optimization of dilute-acid pretreatments and enzymatic saccharification. Bioenerg Res 6(3):1038-1051. doi:10.1007/s12155-013-9337-0

23. Rezende CA, de Lima MA, Maziero P, Deazevedo ER, Garcia W, Polikarpov I (2011) Chemical and morphological characterization of sugarcane bagasse submitted to a delignification process for enhanced enzymatic digestibility. Biotechnol Biofuels 4(1):54. doi:10. 1186/1754-6834-4-54

24. Zhang T, Wyman C, Jakob K, Yang B (2012) Rapid selection and identification of Miscanthus genotypes with enhanced glucan and xylan yields from hydrothermal pretreatment followed by enzymatic hydrolysis. Biotechnol Biofuels 5(1):56

25. Montane D, Farriol X, Salvado J, Jollez P, Chornet E (1998) Fractionation of wheat straw by steam-explosion pretreatment and alkali delignification. Cellulose pulp and byproducts from hemicellulose and lignin. J Wood Chem Technol 18(2):171-191. doi:10. 1080/02773819809349575

26. Chiniquy D, Sharma V, Schultink A, Baidoo EE, Rautengarten C, Cheng K, Carroll A, Ulvskov P, Harholt J, Keasling JD, Pauly M, Scheller HV, Ronald PC (2012) XAX1 from glycosyltransferase family 61 mediates xylosyltransfer to rice xylan. Proc Natl Acad Sci U S A 109(42):17117-17122. doi:10.1073/pnas.1202079109

27. Smith BG, Harris PJ (1999) The polysaccharide composition of Poales cell walls: Poaceae cell walls are not unique. Biochem Syst Ecol 27(1):33-53. doi:10.1016/S0305-1978(98)00068-4

28. Donohoe BS, Decker SR, Tucker MP, Himmel ME, Vinzant TB (2008) Visualizing lignin coalescence and migration through maize cell walls following thermochemical pretreatment. Biotechnol Bioeng 101(5, 1 Decem):913-925. doi:10.1002/bit.21959

29. Gierer J (1986) Chemistry of delignification. Wood Sci Technol 20(1):1-33. doi: 10.1007/bf00350692

30. Shevchenko SM, Apushkinskii AG (1992) Quinone methides in the chemistry of wood. Russ Chem Rev 61(1):105-124

31. Yuan Z, Cheng S, Leitch M, Xu CC (2010) Hydrolytic degradation of alkaline lignin in hot-compressed water and ethanol. Bioresour Technol 101(23):9308-9313. doi:10.1016/j.biortech.2010.06.140

32. Thring RW (1994) Alkaline degradation of ALCELL ${ }^{\circledR}$ lignin. Biomass Bioenergy 7(1-6):125-130. doi:10.1016/0961-9534(94) 00051-T

33. Morreel K, Goeminne G, Storme V, Sterck L, Ralph J, Coppieters W, Breyne P, Steenackers M, Georges M, Messens E, Boerjan W (2006) Genetical metabolomics of flavonoid biosynthesis in Populus: a case study. Plant J 47(2):224-237. doi:10.1111/j.1365-313X.2006.02786.x

34. Ralph J, Quideau S, Grabber JH, Hatfield RD (1994) Identification and synthesis of new ferulic acid dehydrodimers present in grass cell walls. J Chem Soc Perkin Trans 1(23):3485-3498. doi:10.1039/ p19940003485

35. del Río JC, Prinsen P, Gutiérrez A (2013) A comprehensive characterization of lipids in wheat straw. J Agric Food Chem 61(8):1904 1913. doi:10.1021/jf304252m

36. Nuissier G, Bourgeois P, Grignon-Dubois M, Pardon P, Lescure MH (2002) Composition of sugarcane waxes in rum factory wastes. Phytochemistry 61(6):721-726. doi:10.1016/S0031-9422(02) 00356-4
37. Prinsen P, Gutiérrez A, del Río JC (2012) Lipophilic extractives from the cortex and pith of elephant grass (Pennisetum purpureum Schumach.) stems. J Agric Food Chem 60(25):6408-6417. doi:10. 1021/jf301753w

38. Yin $\mathrm{H}, \mathrm{Xu} \mathrm{L}$, Porter NA (2011) Free radical lipid peroxidation: mechanisms and analysis. Chem Rev 111(10):5944-5972. doi:10. $1021 / \mathrm{cr} 200084 \mathrm{z}$

39. Wang K, Yang H, Yao X, Xu F, Sun RC (2012) Structural transformation of hemicelluloses and lignin from triploid poplar during acidpretreatment based biorefinery process. Bioresour Technol 116:99106. doi:10.1016/j.biortech.2012.04.028

40. Jonsson LJ, Alriksson B, Nilvebrant NO (2013) Bioconversion of lignocellulose: inhibitors and detoxification. Biotechnol Biofuels 6(1):16. doi:10.1186/1754-6834-6-16

41. Liu ZL, Slininger PJ, Dien BS, Berhow MA, Kurtzman CP, Gorsich SW (2004) Adaptive response of yeasts to furfural and 5hydroxymethylfurfural and new chemical evidence for HMF conversion to 2,5-bis-hydroxymethylfuran. J Ind Microbiol Biotechnol 31(8):345-352. doi:10.1007/s10295-004-0148-3

42. Demeke MM, Dietz H, Li Y, Foulquie-Moreno MR, Mutturi S, Deprez S, Den Abt T, Bonini BM, Liden G, Dumortier F, Verplaetse A, Boles E, Thevelein JM (2013) Development of a Dxylose fermenting and inhibitor tolerant industrial Saccharomyces cerevisiae strain with high performance in lignocellulose hydrolysates using metabolic and evolutionary engineering. Biotechnol Biofuels 6(1):89. doi:10.1186/1754-6834-6-89

43. Qi X, Zhang Y, Tu R, Lin Y, Li X, Wang Q (2011) High-throughput screening and characterization of xylose-utilizing, ethanol-tolerant thermophilic bacteria for bioethanol production. J Appl Microbiol 110(6):1584-1591. doi:10.1111/j.1365-2672.2011.05014.x

44. Alriksson B, Rose SH, van Zyl WH, Sjode A, Nilvebrant NO, Jonsson LJ (2009) Cellulase production from spent lignocellulose hydrolysates by recombinant Aspergillus niger. Appl Environ Microbiol 75(8):2366-2374. doi:10.1128/AEM.02479-08

45. Haveren J, Scott EL, Sanders J (2008) Bulk chemicals from biomass. Biofuels Bioprod Biorefin 2(1):41-57. doi:10.1002/bbb.43

46. Soto ML, Moure A, Domínguez H, Parajó JC (2011) Recovery, concentration and purification of phenolic compounds by adsorption: a review. J Food Eng 105(1):1-27. doi:10.1016/j.jfoodeng.2011.02. 010

47. Ou S, Kwok K-C (2004) Ferulic acid: pharmaceutical functions, preparation and applications in foods. J Sci Food Agric 84(11): 1261-1269. doi:10.1002/jsfa.1873

48. Rosazza JP, Huang Z, Dostal L, Volm T, Rousseau B (1995) Review: biocatalytic transformations of ferulic acid: an abundant aromatic natural product. J Ind Microbiol 15(6):457-471

49. Hamaguchi M, Cardoso M, Vakkilainen E (2012) Alternative technologies for biofuels production in kraft pulp mills - potential and prospects. Energies 5(7):2288-2309

50. Stamenković OS, Veličković AV, Veljković VB (2011) The production of biodiesel from vegetable oils by ethanolysis: current state and perspectives. Fuel 90(11):3141-3155. doi:10.1016/j.fuel.2011.06. 049

51. White K, Lorenz N, Potts T, Roy Penney W, Babcock R, Hardison A, Canuel EA, Hestekin JA (2011) Production of biodiesel fuel from tall oil fatty acids via high temperature methanol reaction. Fuel 90(11): 3193-3199. doi:10.1016/j.fuel.2011.06.017 